\title{
Utopia, Teoria e Ação: Leitura das Propostas Grupais na Abordagem Centrada na Pessoa ${ }^{1}$
}

Utopia, Theory and Action: Interpretation of The Group Proposals in the Person Centered Approach

Utopía, teoría y acción: lectura de las propuestas grupales en el Abordaje Centrado en la Persona

Maria Luisa

Sandoval Schmidt

Universidade de São Paulo
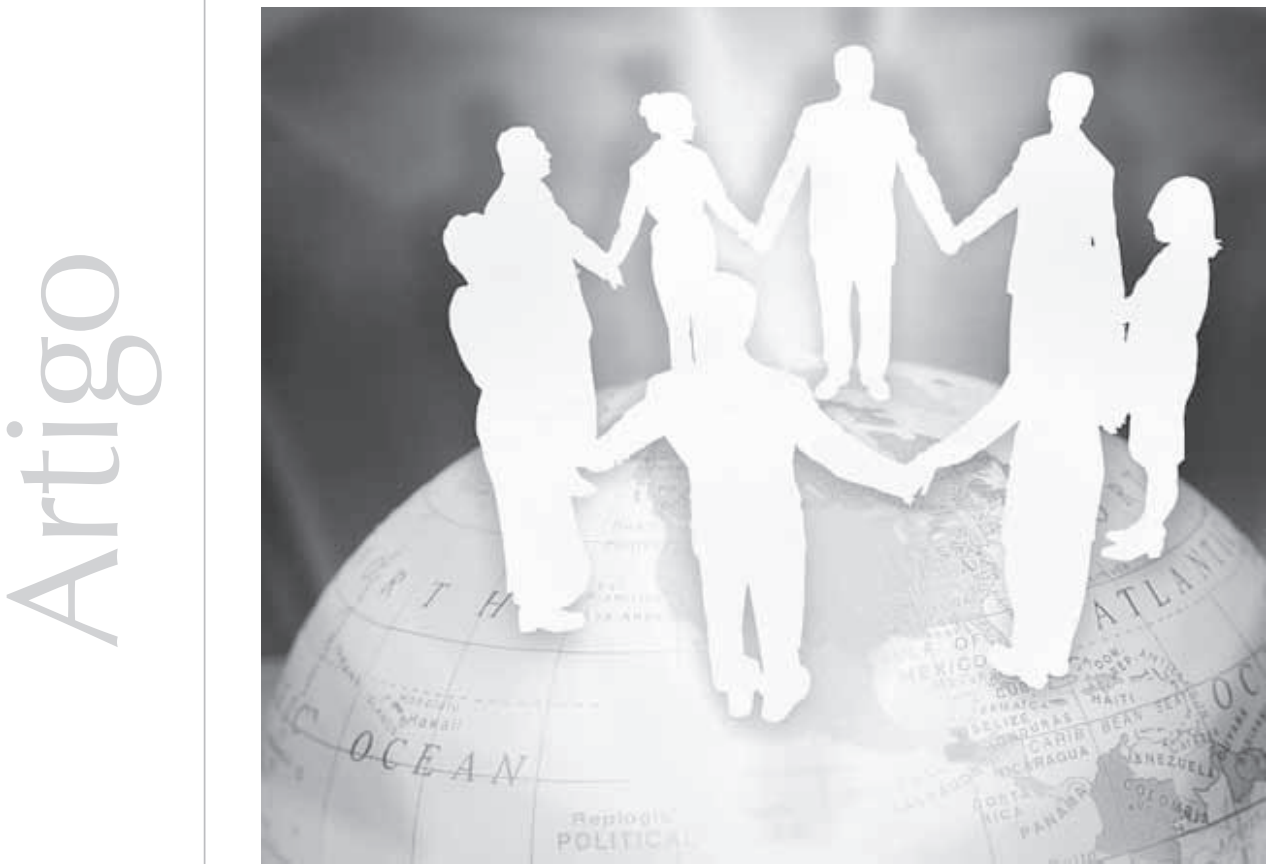
Utopia, Teoria e Ação: Uma Leitura das Propostas Grupais na Abordagem Centrada na Pessoa

1 Este ensaio teve origem em uma comunicação oral feita na comemoração dos 30 anos do Serviço de Aconselhamento Psicológico do IPUSP, realizada entre os dias 18 e 21 de maio de 1999, e fez parte da tese de livre docência Ensaios indisciplinados: aconselhamento psicológico e pesquisa participante, por mim defendida junto ao Instituto de Psicologia da USP em 2005.

Resumo: O presente ensaio analisa as contribuições e os problemas da visão sobre os grupos de Carl Rogers, as concepções de grupo de encontro e de encontro de comunidade e os âmbitos de sua prática, localizandoos em relação à história de constituição da abordagem centrada na pessoa, bem como os conceitos de poder e política construídos por Rogers a partir da psicoterapia centrada no cliente. Da explicitação da trama de ideias e práticas grupais deriva, assim, uma interpretação da presença da utopia e da ideologia no pensamento rogeriano. Essa leitura tem como referência as facetas construtivas e negativas da utopia e da ideologia em suas relações de oposição e complementaridade, tal como tematizadas por Paul Ricoeur. Palavras-chave: Terapia centrada no cliente. Rogers, Carl Ramson 1902-1987. Grupos. Utopias.

Abstract: This essay analyzes Carl Rogers' contributions and vision issues about groups, the conceptions of group meeting and community meeting and the scopes of their practices, locating them in relation to the history of the person centered approach constitution, as well as to the concepts of power and politics developed by Rogers from the psychotherapy focused on the client. From the explicitness of the plot ideas and group practices is then derived an interpretation of the presence of utopia and ideology in the rogerian thought. This interpretation is relative to the constructive and negative aspects of utopia and ideology in its relations of opposition and complementarity, as conceptualized by Paul Ricoeur.

Keywords: Cliente centered therapy. Rogers, Carl Ramson 1902-1987. Groups. Utopias.

Resumen: El presente ensayo analiza las contribuciones y problemas de la visión sobre grupos de Carl Rogers. Trabaja las concepciones de grupo de encuentro y de encuentro de comunidad y los ámbitos de su práctica, ubicándolos en relación a la historia de constitución del Abordaje Centrado en la Persona, así como los conceptos de poder y política construidos por Rogers a partir de la psicoterapia centrada en el cliente. De la explicitación de la trama de ideas y prácticas grupales deriva, de esa manera, una interpretación de la presencia de la utopía y de la ideología en el pensamiento rogeriano. Esta lectura tiene como referencia las facetas constructivas y negativas de la utopía y de la ideología en sus relaciones de oposición y complementación, de la forma como fueron tematizadas por Paul Ricoeur.

Palabras clave: Terapia no dirigida. Rogers, Carl Ramson 1902-1987. Grupos. Utopía.

Rogers considerou a sociedade ideal um ambiente propício ao crescimento e ao desenvolvimento dos indivíduos, cuja base seriam as relações interpessoais fundamentadas na empatia, na autenticidade e na aceitação incondicional positiva. Para ele, a convivência democrática e construtiva entre indivíduos, grupos e nações dependia, quase que exclusivamente, dessas qualidades das relações interpessoais descobertas na psicoterapia.

A partir do final dos anos 60, seu interesse pelo aconselhamento e pela psicoterapia individuais deslocou-se e concentrou-se, cada vez mais, nos grupos, com os quais já vinha trabalhando, principalmente na formação de psicólogos e psicoterapeutas, talvez como resposta ao reconhecimento dos limites do setting dual (conselheiro/terapeuta e cliente) em relação à pauta ambiciosa de transformações sonhadas para a vida social.

A crescente dedicação de Rogers ao trabalho com grupos veio acompanhada de uma atenção, também, ao tema da necessidade de maior liberdade nas instituições educacionais.

Essa consideração pelos grupos, ao mesmo tempo, fez parte de um movimento maior, de uma espécie de boom das experiências de grupo, que atravessou os anos 70 e que permeou diversas esferas das práticas psicológicas e psicoterapêuticas.

No livro Grupos de encontro, cuja primeira edição é de 1970, Rogers condensa ideias e experiências em torno dos chamados grupos de encontro, bem como busca localizá-los em suas origens e estabelecer as diferenças entre esse tipo de trabalho grupal e outros que se tornavam conhecidos no âmbito das práticas psicológicas. $\mathrm{O}$ autor trata, ainda, dos efeitos que a eles se poderia atribuir no contexto da sociedade norte-americana e, talvez, alhures, dependendo de sua expansão. Seu exame é útil para um inventário crítico das contribuições e dos problemas da visão rogeriana sobre grupos. 
Os grupos de encontro afirmaram-se em meio a outros tantos experimentos com grupos, tais como os T-groups ou grupos-T - abreviação de sensibility training ou treino de sensibilidade -, os laboratórios de relações humanas e workshops ${ }^{2}$ de lideranças, educação ou aconselhamento, os grupos gestálticos, os de percepção sensorial e corporal, os de movimento corporal, aqueles que são centrados na tarefa e os de desenvolvimento da organização e de formação de equipe, entre outros.

Desse conjunto de tendências, Rogers (1972) destaca os grupos-T, concebidos por Kurt Lewin no Massachusetts Institute of Tecnology e na Universidade de Michigan, como início e principal influência do movimento de grupos, que se tornou mais evidente a partir dos anos 60 e $70^{3}$.

A proposta de Kurt Lewin, nos anos 40, consistiu em um treinamento em relações interpessoais para gerentes e lideranças de indústrias. Inspirado por essa proposta, Rogers começou a praticar, entre 1946 e 1947, o treinamento de conselheiros do Centro de Aconselhamento Psicológico da Universidade de Michigan.

Comparando sua atividade de grupo com a de Kurt Lewin, Rogers sugere que os grupos-T acentuavam as capacidades dos indivíduos para as relações interpessoais, enquanto o grupo de encontro ou grupo de encontro básico enfatizava o crescimento pessoal e o desenvolvimento e aperfeiçoamento da comunicação e das relações interpessoais por meio de um processo experiencial que, por um lado, buscava combinar o treino

2 Trata-se de oficinas com temáticas específicas.

3 Para uma visão mais detalhada das ideias de Kurt Lewin, ver Lewin, 1983, 1985 psicoterapia de grupos coincidiu com a passagem da psicoterapia centrada na pessoa para a abordagem centrada na pessoa, na qual o tema das relações interpessoais passa a ser tratado no âmbito mais largo da educação, das instituições de produção e das relações interculturais e internacionais. Dito de outra maneira, o trabalho com grupos não era alheio a Rogers como dispositivo de formação de psicoterapeutas e dispositivo psicoterapêutico, porém, passou a ser a via, por excelência, de seu desejo de influenciar e transformar instituições partindo da mudança dos indivíduos, das pessoas. Nessa passagem, o referencial teórico permanece o mesmo, expandindo-se os propósitos de transformação.

Rogers acreditava, ainda, que o movimento dos grupos de encontro havia crescido à margem do establishment, da formalidade e do caráter oficial das indústrias, universidades, instituições educacionais e religiosas, agências governamentais e penitenciárias nas quais, paradoxalmente, encontraram acolhida. Esse crescimento foi atribuído à possibilidade que tais grupos ofereciam de expressar as necessidade e os desejos das pessoas contra as necessidades das instituições. No contexto norte-americano, foi, inclusive, tomado como um movimento ameaçador tanto à psiquiatria e à Psicologia clínica de cunho autoritário quanto aos políticos de direita, que o consideraram uma espécie de conspiração comunista.

De acordo com Rogers, os grupos de encontro foram um verdadeiro pesadelo para a direita norte-americana e para todos aqueles que temiam qualquer tipo de mudança. Em suas palavras:

(...) Os grupos de encontro conduzem a maior independência pessoal, a menos sentimentos escondidos, a maior interesse em inovar, a maior oposição à rigidez institucional. Por isso, se uma pessoa receia, sob qualquer forma, a mudança, receia justamente os grupos de encontro (Rogers, 1972, p. 25) 
A justificativa para a difusão dos grupos, que, alocados em instituições e agências governamentais, não recebiam destas apoio financeiro, reside, no entender de Rogers, na oposição que as pessoas precisam e querem fazer às instituições e na "fome de relações próximas e verdadeiras,

onde sentimentos e emoções possam se manifestar espontaneamente" (Rogers, 1972, p. 23).
A justificativa para a difusão dos grupos, que, alocados em instituições e agências governamentais, não recebiam destas apoio financeiro, reside, no entender de Rogers, na oposição que as pessoas precisam e querem fazer às instituições e na "fome de relações próximas e verdadeiras, onde sentimentos e emoções possam se manifestar espontaneamente" (Rogers, 1972, p. 23). Considerando a crescente desumanização da cultura norte-americana, que leva à impessoalidade das relações, e o conforto econômico, que leva os indivíduos a se preocuparem e a se ocuparem de suas necessidades psicológicas, Rogers explica o interesse pelos grupos como derivado de uma poderosa fome dos que não têm fome de comida e não sofrem carências materiais.

A oposição às instituições e a expressão emocional livre e autêntica são, na perspectiva rogeriana, os objetivos dos grupos de encontro e de seus principais usuários, a população economicamente mais abastada.

$\mathrm{Na}$ avaliação dos efeitos dos grupos de encontro, fica patente a consideração do grupo como um setting para o crescimento pessoal dos indivíduos. Esses efeitos são descritos por Rogers (1972) como: apoderamento dos sentimentos, atualização do eu, autodeterminação, compromisso e direção interiores, autoaceitação e autoestima, congruência entre o eu percebido e o eu ideal, confiança, diminuição do autoritarismo em relação aos outros, maior aceitação dos outros, menor interesse no controle de outros e maior interesse na participação de outros e maior competência para o trabalho em equipe. O pressuposto era o de que as mudanças alcançadas pelos indivíduos que frequentavam os grupos de encontro provocariam ressonâncias nos âmbitos familiares e institucionais nos quais esses indivíduos viviam. Porém, ao mesmo tempo, a avaliação empreendida pelo próprio Rogers indica, por um lado, que havia dificuldade por parte dos indivíduos de conservarem suas mudanças e experiências construtivas no retorno a seus ambientes naturais, e, por outro, que transformações institucionais dignas de nota só ocorreram em algumas situações em que o trabalho envolveu um grupo fechado, ou seja, um grupo institucional ou natural.

O grupo de encontro, assim como a psicoterapia, constitui um espaço de vida social que se destaca da vida comum por suas características positivas com relação à possibilidade de expressão emocional compartilhada de pessoas que, no entanto, não se mantêm em convívio fora do grupo e nem se organizam para uma ação conjunta junto às instituições nas quais vivem e trabalham. Dessa forma, esses experimentos grupais oferecem-se muito mais como uma alternativa, temporária e circunscrita, à vida institucional, funcionando, talvez, como exemplo de convivência social que, no entanto, não resiste aos dispositivos de poder e de organizacão hegemônicos nas instituições onde a vida dos indivíduos acontece. No plano da intervenção, inexiste confronto ou interlocução com as instituições, mas sim, a enunciação de uma espécie de experiência paralela que pode evidenciar, para os indivíduos, conflitos entre suas necessidades e seus desejos e as rotinas institucionais. No plano teórico, as instituições permanecem desconhecidas, na medida em que são apreendidas como meras cerceadoras do crescimento pessoal.

Os grupos de encontro, na medida em que podem ser definidos como a convivência autogestionada de um grupo de seis a doze pessoas que se reúnem, semanalmente, durante uma e meia a duas horas, com o objetivo de conversarem sobre suas experiências, conflitos e dificuldades na esfera do relacionamento interpessoal, sob os cuidados de um facilitador, são, na 
verdade, a versão grupal da psicoterapia e do aconselhamento individual professado pela psicoterapia centrada no cliente.

Assim como a psicoterapia rogeriana abraça finalidades formativas e não propriamente curativas, os grupos também o fazem, propiciando uma aprendizagem significativa que serve tanto aos propósitos de lidar com o sofrimento psicológico quanto àqueles de formação de profissionais das áreas da saúde e da educação, esferas nas quais foram, e são ainda, largamente usados. Essa observação parece relevante, pois mostra, mais uma vez, como os fundamentos da prática psicoterápica, na forma peculiar em que a desenha Rogers (1975), são, para ele, a base de onde projeta sua visão de transformação social. O fator numérico é, aqui, decisivo: quanto mais pessoas forem atingidas por essa prática, maiores as chances de mudanças visíveis no terreno social.

Na ampliação do campo de influência dos grupos, parece, portanto, importante a opção que Rogers e seus colaboradores ${ }^{4}$ fizeram, a partir de 1973, de se dedicarem à facilitação de encontros de comunidade ou comunidades de aprendizagem. Estas, diferentemente dos grupos de encontro, reuniam um número grande de pessoas, de 100 a 250, para uma convivência autogestionada intensiva durante uma semana ou mais, em regime de alojamento comunitário, com a presença de uma equipe de facilitadores. A disposição e as escolhas pessoais eram critérios para a participação nos encontros, o que, de certa forma, radicalizava, em relação aos grupos de encontro, a ênfase nos indivíduos independentemente de seus laços sociais de origem.

4 Os primeiros a realizarem esse tipo de encontro foram, segundo Wood (1983):

Natalie Rogers, Carl

Rogers, John Keith

Wood, Alan Nelson e Betty Meador. católicos e protestantes em Belfast, e o encontro de Arcozelo, no Brasil, em 1977.

Os encontros de comunidade coroam, podese dizer, um itinerário de afastamento das instituições, tanto como contexto dos e para os grupos, quanto como objeto pertinente de estudos e pesquisas: as comunidades de aprendizagem consagram-se como verdadeiros laboratórios da vida social, criando condições especiais para a prática e o estudo de uma psicologia social centrada na pessoa.

Em 1977, Rogers declara seu recente interesse pela política das relações interpessoais, pois, até então, de acordo com confissão feita no livro Sobre o Poder Pessoal, não percebia as dimensões políticas de suas proposições.

(...) Tenho praticado e ensinado política durante toda a minha vida profissional, e nunca me dei conta totalmente disso até agora (Rogers, 1978, p. 13)

Passa, dessa forma, à indagação, mais sistemática, sobre os efeitos políticos das práticas da terapia centrada no cliente, do ensino centrado no aluno e da abordagem centrada na pessoa.

O alicerce da revolução política da psicoterapia centrada no cliente, segundo o autor, reside na confiança nas capacidades de crescimento, autocompreensão e autorregulação dos organismos humanos. As atitudes preconizadas como necessárias e suficientes para desencadear um processo de crescimento traduzem, politicamente, a facilitação da passagem do controle heterônomo para o autocontrole. $\mathrm{Na}$ educação, de modo análogo, a presença dessas mesmas atitudes, por parte dos educadores, seria responsável por uma aprendizagem autodirigida dos alunos, na qual aprender a aprender é mais importante do que adquirir conteúdos programáticos. 
Nos grupos e, especialmente, nos encontros de comunidade ou comunidades de aprendizagem, a política diz respeito aos efeitos de poder e de controle interpessoais que propiciam ou impedem a liberdade pessoal e a liberdade para aprender.

É interessante notar que a extensão das atividades de Rogers e de seus colaboradores para o âmbito dos grandes grupos provoca a discussão e a reflexão sobre o âmbito político de suas práticas. Essa discussão, contudo, parece apenas explicitar aquilo que já estava latente na psicoterapia como uma política não nomeada como tal. Identificar e nomear uma qualidade e uma intenção políticas é um gesto tardio de Rogers que clarifica sua crença na capacidade da Psicologia de operar transformações sociais, focalizando a resolução de conflitos. A amplitude do horizonte utópico em que essas transformações se projetam, no imaginário rogeriano, é inversamente proporcional à simplificação que faz da política. Sua definição de política diz que ela é

Em resumo, o processo de obter, compartilhar ou abandonar poder, controle, tomada de decisão. É o processo das interações e efeitos altamente complexos desses elementos, da forma como existem nos relacionamentos entre pessoas, entre uma pessoa e um grupo, ou entre grupos (Rogers, 1978, p. 14)

A política da psicoterapia, revelada no exame retrospectivo, é o fundamento e a referência para essa conceituação geral da política, ou seja, a política, teoricamente e na prática, é elucidada pela política da abordagem centrada na pessoa que, por sua vez, é estabelecida pela política da psicoterapia centrada na pessoa. Nas palavras de Rogers:

A política da abordagem centrada-nocliente implica que o terapeuta evite e renuncie conscientemente a qualquer controle sobre, ou a qualquer tomada de decisão pelo cliente. Trata-se da facilitação da posse de si mesmo pelo cliente e das estratégias pelas quais isso pode ser alcançado; a colocação do locus da tomada de decisão, e a responsabilidade pelos efeitos dessas decisões é politicamente centrada-no-cliente (Rogers, 1978, p. 22)

A confiança nas capacidades de autoconhecimento e autorregulação do indivíduo que formam o substrato da política da abordagem centrada na pessoa encontra sua contrapartida na autossuficiência da teoria psicológica para definir a política em um sentido amplo.

Essa política foi, sem dúvida, decisiva para o questionamento do poder do especialista. Por um lado, por meio da gravação das entrevistas de ajuda psicológica que "permitiu que uma brisa de ar puro e de senso comum perpassasse o mundo terapêutico" (Rogers, 1978, p. 23) dando publicidade aos dispositivos da psicoterapia, Rogers combateu o segredo e o caráter inquestionável dos atos do psicoterapeuta profissional; por outro, escolhendo uma conduta terapêutica pautada pelo constante exame crítico da posição do terapeuta em relação ao poder e ao controle exercidos sobre o cliente em nome de teorias de desenvolvimento, de personalidade ou de psicopatologia. Rogers admite que o questionamento do poder do especialista ocupa lugar central na política da psicoterapia centrada no cliente:

Levei anos para reconhecer que a oposição violenta à terapia centrada-no-cliente procedeu não apenas de sua novidade, e do fato de provir de um psicólogo e não de um psiquiatra, mas principalmente do fato de atacar violentamente o poder do terapeuta (Rogers, 1978, p. 24)

Junto a tendências psicoterápicas claramente autoritárias, como uma certa psicanálise médica e ortodoxa praticada nos Estados Unidos e o behaviorismo, com seu entusiasmo em torno dos efeitos do controle do comportamento, e outras, ambíguas e 
confusas quanto ao poder do especialista, a abordagem centrada no cliente representou uma espécie de vanguarda.

A ideia de uma suspensão do controle e do poder de decisão, por parte do terapeuta, no setting psicoterápico, cunhando a figura do facilitador, é transposta para o âmbito dos grupos de encontro, encontros de comunidade e grupos para resolução de conflitos interculturais.

Nessa transposição, Rogers busca uma aplicação em larga escala dos mesmos princípios que, para ele, se mostraram eficazes na resolução de conflitos em pequena escala. Nessa transposição, ainda, visualiza-se com mais clareza a psicologização da política, uma vez que, para Rogers, os conflitos econômicos, ideológicos, de Justiça ou a violência revolucionária podem ser superados fazendo apelo à base humana comum a todos os indivíduos que encontram, nos grandes grupos, a oportunidade de se depararem com ela.

A política de confronto para tomada-dedecisão muda completamente quando cada pessoa tem o poder de ser integralmente ela mesma - com sentimentos, medos, idéias, esperanças, desconfianças. A decisão é, então, tomada a partir de uma base humana, não como conseqüência de um conflito político (Rogers, 1978, p. 125)

Um encontro, conduzido por Rogers, entre cinco protestantes e quatro católicos em Belfast é o modelo ou exemplo daquilo que o autor entende ser uma tecnologia plenamente desenvolvida pela abordagem centrada na pessoa, cuja aplicação em larga escala mudaria a feição do mundo. O seu comentário a essa experiência não deixa dúvidas quanto à sua crença na eficácia, em proporção planetária, dos grupos de encontro interculturais.
O fato de um grupo ter caminhado no sentido da reconciliação não terminou com as matanças em Belfast. É verdade; mas suponhamos que houvesse mil ou dois mil grupos. A despesa seria uma fração do que os exércitos particulares católicos, o exército de ocupação britânica e os exércitos particulares protestantes têm custado. Quanto aos facilitadores, há centenas deles já suficientemente treinados e que, se fossem avisados com três meses de antecedência, poderiam dedicar-se à tarefa (Rogers, 1978, p. 131)

A base humana - sentimentos universais, escuta incondicional, compreensão das razões do outro - sustentaria a superação de limites e as diferenças culturais, religiosas, étnicas e nacionais envolvidas nos conflitos que, em última instância, podem e devem ser interpretados como conflitos interpessoais que se oferecem à aproximação psicológica.

Ao concluir o capítulo sobre tensões interculturais do livro Sobre o Poder Pessoal, Rogers professa, mais uma vez, sua confiança nos dispositivos psicoterapêuticos para a resolução de conflitos sociais.

\begin{abstract}
Espero ter conseguido demonstrar que existem modelos para o tratamento eficaz de quase toda variedade de tensões intergrupais. Quer estejamos falando de diferenças religiosas, quer do rancor baseado na pobreza versus riqueza, quer da desconfiança enraizada nas diferenças de costumes culturais, quer da crescente fúria em ebulição da discriminação racial, quer dos seculares conflitos mortais envolvendo vários desses elementos, não desconhecemos, nem nos falta experiência, quanto à utilização de habilidades interpessoais que ajudam a solucionar essas tensões (Rogers, 1978, p. 136)
\end{abstract}

Assim como na proposição dos encontros de comunidade, observa-se uma tendência a abordar as instituições de um ponto de vista abstrato; nos grupos interculturais, as diferenças culturais, étnicas, religiosas 
5 Convém destacar que a definição psicológica de indivíduo ou pessoa, como prefere Rogers, deriva da noção de organismo. O modo como organismo e cultura se opõem no pensamento rogeriano é teoricamente importante, reforçando suas tendências de redução do social ao psicológico. Sobre essa questão, ver Schmidt, 2005.

6 Pela equação básica, Rogers professa a ideia de que determinada situação psicossocial propiciada pelas atitudes de empatia, congruência e aceitação incondicional é condição necessária e suficiente para que um processo de mudança e crescimento ocorra nos indivíduos. e nacionais são tratadas como objeto de uma superação possível por meio da livre expressão de sentimentos e de emoções. De uma certa maneira, reduz-se os conflitos culturais, étnicos, religiosos e internacionais a conflitos interpessoais na mesma medida em que se circunscreve a definição de indivíduo à esfera psicológica. ${ }^{5}$

As experiências com grupos não instigaram a pesquisa teórica, uma vez que a compreensão dos fenômenos grupais permaneceu encapsulada no círculo fechado da equação básica rogeriana ${ }^{6}$. Como desafio prático, porém, essas experiências foram largamente relatadas por Rogers e seus colaboradores, que investiram nos relatos para demonstrar a verdade e a eficácia dos mesmos princípios e pressupostos válidos para a psicoterapia.

Burrhus Frederic Skinner (1975) escreveu, em 1948, o livro Walden II: uma Sociedade do Futuro, no qual, de forma romanceada, projetou a sociedade de seus sonhos, administrada por especialistas do comportamento.

O caminho de Rogers parece ter sido algo diferente no que diz respeito à projeção de uma teoria psicológica no plano da utopia: pensou, talvez, em realizá-la no aqui e agora dos grupos em que pessoas se encontravam a si mesmas, em um contexto de suspensão do mundo social, cultural e institucional desumanizado. Naquela atmosfera rarefeita de um grupo recortado contra o mundo, o encontro autêntico entre pessoas tornava-se possível e, ao mesmo tempo, exemplar para a saúde das sociedades humanas.

Paul Ricoeur (1989), no ensaio A Ideologia e a Utopia: duas Expressões do Imaginário Social, analisa duas figuras do imaginário social e cultural, ideologia e utopia, que, de forma complementar, operam modos de lidar com o passado, com o futuro e com as iniciativas do presente.

Buscando salientar a função social dessas figuras do imaginário coletivo, destaca que ambas possuem tanto uma função construtiva quanto outra, negativa.

A ideologia, sendo sempre uma interpretação da vida social, presta-se à sua falsificação ou distorção, bem como à legitimação do poder e da autoridade. A essas funções, amolda-se o sentido negativo da ideologia como mentira social e ilusão protetora do status quo. Ao mesmo tempo, porém, a ideologia constitui a estrutura simbólica da memória social, cumprindo uma função integradora. De acordo com Ricouer:

\begin{abstract}
Todo grupo se mantém, quero dizer, se mantém de pé, adquire uma consistência e uma permanência, graças à imagem estável e durável que ele se dá de si mesmo. Essa imagem estável e durável exprime o nível mais profundo do fenómeno ideológico (Ricouer, 1989, p. 379)
\end{abstract}

Em sua faceta negativa, representa a crença coletiva subtraída à crítica e, em sua faceta positiva, a construção de uma imagem idealizada na qual se configura a identidade de um grupo ou de uma sociedade.

Se a ideologia preserva, replica e reforça o estatuto social presente, com base em uma interpretação do passado, à utopia cabe imaginar um outro lugar e um outro tempo que se propõem como alternativa à realidade presente. Seu sentido positivo consiste no questionamento da ordem econômica, social, política, cultural e religiosa existente, promovendo um 
exercício imaginativo sobre um outro modo de ser do social e sobre as formas de exercer o poder.

Seu sentido negativo repousa, por um lado, "na ausência de toda reflexão de caráter prático e político sobre os apoios que pode encontrar no real existente" (Ricouer, 1989, p. 383), e, por outro, na criação de esquemas constrangedores do pensamento que se constituem, igualmente, pela ausência de constrangimentos do real. Nesse caso, o caráter destrutivo da utopia reside no risco de uma paralisia tanto da ação quanto do pensamento.

Para retomar o sentido libertário da utopia, abaixo ou por detrás de suas caricaturas totalitárias, Ricouer pensa ser útil encarála como uma espécie de mediadora entre a esperança e a tradição, definindo-a como "aquilo que impede o horizonte de expectativa de se fundir com o campo da experiência" (1989, p. 384).

Da explanação de Ricouer, ideologia e utopia emergem como figuras da tensão, no imaginário, entre uma função de integração e uma função de subversão e, portanto, em uma relação de complementaridade que, no entanto, não se esgota nesse paralelismo, pois, como observa o autor, as formas patológicas da ideologia e da utopia, identificadas como figuras da falsa consciência, podem ser criticadas, de maneira cruzada e recíproca, a partir de suas formas construtivas. Em suas palavras:

Parece, de facto, que temos sempre necessidade da utopia, na sua função fundamental de contestação e projecção num algures radical, para levar a bom termo uma crítica, igualmente radical, das ideologias. Mas a recíproca é verdadeira. Tudo se passa como se, para curar a utopia da loucura em que ela, incessantemente, corre o risco de cair, fosse preciso invocar a função sã da ideologia, a sua capacidade de dar (a) uma comunidade histórica o equivalente daquilo a que poderíamos chamar uma identidade narrativa (Ricouer, 1989, p. 385)

Essa breve referência ao ensaio de Ricouer oferece alguns elementos preciosos para uma interpretação do imaginário rogeriano sobre os grupos.

Olhando retrospectivamente, parece que as experiências grupais foram encaradas como realizações pontuais e microscópicas de uma visão utópica da vida social, realizações que se davam no aqui e agora do processo de cada grupo.

Curiosamente, não era no plano teórico que essa visão travava seu embate com a ordem estabelecida, mas, sim, no plano da ação, pois as experiências grupais e o seu relato ocuparam o lugar da teoria, cumprindo o papel de projetar no horizonte dos possíveis uma organização social baseada no poder pessoal. A rigor, inclusive, os ideais e a subcultura dos grupos de encontro e dos encontros de comunidade não se colocam contra a ordem social, atacando as formas da existência familiar, a organização da vida política, o modo de produção material e a religião; ao contrário, fazem vistas grossas à ordem social implicada na desumanização das relações interpessoais, acreditando que a mudança das relações interpessoais muda a ordem social ou, mais precisamente, investindo na mudança das relações interpessoais, mantendo a ordem social.

Se não se trata da proposição de uma sociedade alternativa mas, muito mais, da apresentação de uma alternativa para as relações interpessoais que, em tese, serve a qualquer sociedade, por que falar em utopia? Talvez para ter a oportunidade de 
desvelar uma singularidade da tensão entre a função integradora e a função subversiva de uma teoria e de uma prática psicológicas, tentando, ao mesmo tempo, fazer-lhes a crítica.

O movimento dos grupos de encontro, nos anos 60 e começo dos 70, na vigência da guerra fria entre Estados Unidos e União Soviética, despertou ataques virulentos por parte de setores da direita norte-americana no Congresso e na imprensa escrita. Rogers faz menção à leitura, no Congressional Record, de um texto de Ed Dieckmann Jr. chamado Sensibilidade Internacional: uma Rede para o Controle Mundial, no qual, entre outras coisas, o autor afirma ser um dos objetivos do movimento "o envolvimento de toda a comunidade num gigantesco laboratório de grupos, exactamente como no Vietname do Norte, Rússia e China Vermelha" (1970, p. 24). Outras declarações na imprensa associam-no a uma conspiração de esquerda, à lavagem cerebral, à terapia do ódio e ao controle ditatorial do nazismo e do socialismo.

Esses fatos tendem a mostrar que os grupos de encontro, naquele contexto histórico, significaram, no imaginário de facções reacionárias norte-americanas, uma ameaça à ordem capitalista e à mentalidade liberal. Rogers, contudo, interpretou o temor daqueles que atacavam os grupos de encontro dentro do círculo restrito de sua visão psicológica de mudança: para ele, temia-se a independência pessoal, a expressão de sentimentos, o interesse em inovar e a oposição à rigidez institucional.

Os grupos de encontro cabe lembrar, embora não fossem sustentados por qualquer tentativa de compreensão teórica das instituições, atuaram em vários contextos institucionais, tais como aqueles representados por universidades, escolas, empresas e indústrias, exército, entidades religiosas, hospitais e clínicas, entre outros. É possível, no caso dos grupos de encontro e dada sua inserção institucional, supor uma dinâmica singular em que a teoria psicoterápica rogeriana entrincheirava-se em seu esquematismo, negando qualquer especificidade aos contextos institucionais e recusando qualquer necessidade de revisão ou de ampliação de seu pensamento sobre os processos de mudança, enquanto a multiplicação das ações esbarrava, concretamente, nos constrangimentos institucionais.

Parece plausível pensar que a proposição dos encontros de comunidade ou comunidades de aprendizagem evadiu-se desses constrangimentos institucionais, manteve intato o esquema teórico e amplificou o idealismo visionário das ações.

É interessante lembrar que os encontros de comunidade nasceram na mesma época em que Rogers se desvencilhou definitivamente do vínculo que havia mantido com instituições universitárias ao longo de sua vida profissional, instituições com as quais manteve relações produtivas, mas tensas, criando o Centro de Estudos da Pessoa, onde, com a ajuda de outros pesquisadores e psicoterapeutas, procurou desenvolver seus trabalhos com mais independência.

Os encontros de comunidade representaram uma radicalização, sem dúvida ousada, da aplicação das mesmas ideias concebidas na esfera da psicoterapia e da confiança em seus efeitos transformadores. Neles, o caráter intransigente e simplificador do pensamento de Rogers não foi questionado, uma vez que cada encontro foi narrado e avaliado de modo a comprovar a força de suas concepções .

No imaginário dos encontros de comunidade, a vivência ocupou, também, o lugar da atividade intelectual e de pensamento. Na vivência dos encontros, o horizonte de expectativas coincidia com a experiência, fazendo crer que o ideal das relações interpessoais encontrava ali sua realização. 
A essa vivência, renovada a cada encontro, Rogers atribuiu o valor de uma verdadeira revolução nas relações interpessoais e nas relações de poder entre especialistas e leigos, antevendo, nas experiências singulares dos grupos autogestionados, a forma perfeita de associação entre homens, grupos e nações, considerando, ainda, que dispunha, com seu modo de conduzir os grupos, de uma tecnologia simples e pronta para o uso em grande escala na esfera dos conflitos intragrupais, intergrupais, internacionais e transculturais.

Isso sintetiza a faceta utópica da proposição rogeriana para o trabalho com grupos que, no entanto, ao se afastar das instituições, evita pensar nas barreiras sociais, econômicas, políticas e ideológicas que impedem as boas relações interpessoais. A teoria psicológica que busca dar coerência a uma tal proposição, por sua vez, dispensa o auxílio de outras áreas do conhecimento humano, reduzindo as chances de alcançar algum esclarecimento sobre as dimensões sociais, culturais, econômicas, históricas e políticas que comprimem o idealismo de uma visão que se pretende exclusivamente psicológica.

O intento de Rogers foi, talvez, o de mudar psicologicamente as relações interpessoais sem com isso ter que se confrontar com a ordem social. A função subversiva de suas ideias e práticas permaneceu limitada ao âmbito da política das profissões de ajuda e da educação.

O complemento ideológico dessas ideias e práticas cumpriu, ao que parece, a função de conservar a ideologia liberal e capitalista, por um lado, ao colocar os ensaios com grupos a serviço dos indivíduos e de seu mundo privado de sentimentos, e, por outro, a de apostar em uma humanização do capitalismo. 
Maria Luisa Sandoval Schmidt

Mestre e Doutora em Psicologia Escolar e do Desenvolvimento Humano pela Universidade de São Paulo.

Professora Associada da Universidade de São Paulo, São Paulo - SP - Brasil.

E-mail: maluschmidt@terra.com.br

\section{Endereço para envio de correspondência:}

Universidade de São Paulo, Instituto de Psicologia, Departamento de Psicologia da Aprendizagem do Desenv. da Personalidade.

Av. Prof. Mello Moraes, 1721 Cidade Universitária, Sao Paulo, SP - Brasil. CEP 05508-900.

Recebido 2/12/2010, Aprovado 16/5/2011.

Lewin, K. (1965). Teoria de campo em ciência social. São Paulo: Pioneira.

Lewin, K. (1983). Problemas de dinâmica de grupo. São Paulo: Cultrix.

Ricoeur, P. (1989). Do texto à ação: ensaios de hermenêutica II. Porto: Rés-Editora

Rogers, C. R. (1972). Grupos de encontro. Lisboa: Moraes Editores.

Rogers, C. R. (1975). A terapia centrada no paciente. São Paulo: Martins Fontes.

Rogers, C. R. (1978). Sobre o poder pessoal. São Paulo: Martins Fontes.
Schmidt, M. L. S. (2005). Apontamentos críticos à teoria da mudança de Carl Rogers. In Ensaios indisciplinados: aconselhamento psicológico e pesquisa participante. Tese de Livre Docência, Instituto de Psicologia da Universidade de São Paulo, São Paulo.

Skinner, B. F. (1975). Walden II: uma sociedade do futuro. São Paulo: E.P.U.

Wood, J. K. (1983). Terapia de grupo centrada na pessoa. In C. R. Rogers, J, K. Wood, M. M. O'Hara, \& H. L. da Fonseca, Em busca de vida. São Paulo: Summus. 